\title{
Blending Social Learning System into Foreign Language Educational Platform
}

\author{
Jeong-ryeol Kim \\ Korea National University of Education \\ jrkim@knue.ac.kr
}

\begin{abstract}
This paper is to address the changes of educational platform with the introduction of smart technology. In particular, it investigates the blending of social learning system into the traditional structured classroom. Schoolfy is used to transform the structured classroom for the blending. The effects were looked into for the areas of listening, speaking, reading and writing in the single group pre/post test result comparison. The effects in all skills were big in effect size, but it demonstrates issues of teacher participation for the interaction. Educational platform is a second teacher who helps enhance the interaction between teacher and students by introducing rich resources and inviting students for a deep engagement of exploration. Educational platform provides the basis of experiencing $21^{\text {st }}$ century skills.
\end{abstract}

Keywords: educational platform, smart technology, changes in education

\section{Introduction}

"Those who educate children well are more to be honored than they who produce them; for these only gave them life, those did the art of living well." said Aristotle. Teachers play a very important role in our education. Being a successful teacher is quite an accomplishment in itself. However, a teacher to be successful requires supports in different directions including technical platform and materials.

Schools have undergone an evolutionary path having adapted to the technological advancement at the time. The current educational platform is the evident evolutionary path of teaching and learning between generations and their contextual changes. Language is an instrumental tool mediating all kinds of learning. Human being is the only species who can describe the event in the past, deceive others and dream of the future in their minds and language. This study is a conceptual travel to the future classroom where the minds meet to process the language of the people in an educational platform using smart technology.

Entry of technology into educational system has reduced their struggle and made their work better despite the complaints over the increased administrative work. Social learning system provides an opportunity for the great educational platform which saves their precious time and effort. Social learning platform is a free educational platform that welcomes teachers across the world into its community.

This paper explores a blending of social learning system into a foreign language educational platform where structured language learning classes are combined with experiential interactions with peers and others. It will describe the conceptual framework of the integration of social learning with structured classroom learning. Following the conceptual framework, the paper will discuss an analysis of effects of using Schoolfy for a blended model in the areas of interest, confidence, motivation and collaboration of students in the class. 


\section{Conceptual Framework}

Integrating social learning into structured school-based learning represents a major change in the way students excel their learning of contents and other mediating languages in authentic environments. However, researches are in dispute regarding how to get to the formal learning model blended with a social learning system[1-3]. A good way to begin is to discuss what a social learning model is or should be like to expand the structured school experiences of students.

The concept of community of practice was not born in the systems theory tradition. It has its roots in attempts to develop accounts of the social nature of human learning inspired by anthropology and social theory $[4,5]$.

However, a social learning model will not replace traditional formal learning. Companies will still need to create, deliver, manage, and report on certification and compliance initiatives. Physical classrooms, virtual classrooms, and web-based training (WBT) will all still be appropriate vehicles for content delivery, and instructional designers will still need to determine which approach to use. To move toward a social learning model, one way is to socialize the formal learning that happens through courseware, curriculum, and certifications by embedding social learning inside formal content or wrapping social media around formal content.

For example, WBT often removes all opportunities for social networking and interaction with colleagues, dramatically reducing the benefits that come from diversity of perspective and sharing of ideas and real-world experiences. Embedding social media within WBT courses reintroduces these social exchanges without sacrificing the cost savings or ability to "replay" content.

So what type of social media should be considered for use within the learning function? While there is a broad social media landscape, let's look at several categories of social media to demystify this topic. The categories you decide to facilitate for social learning will depend on your educational goals, what you are trying to achieve and how willing to accept these technologies your schools and learners are. The social learning tools can be classified as in Figure 1.

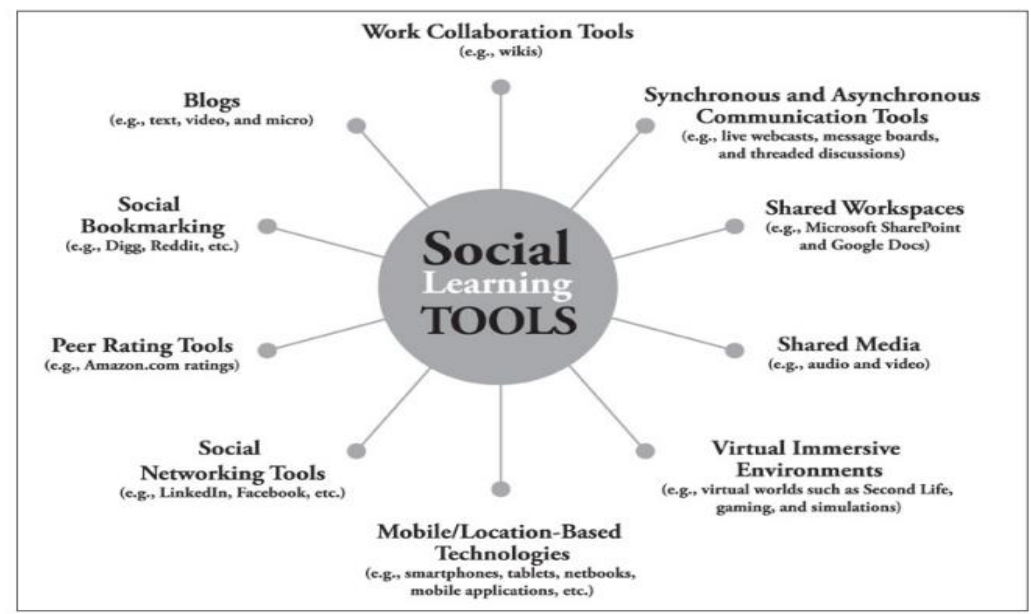

Figure 1. Categories of Social Media

While Figure 1 illustrates general categories of social media, keep in mind that there is a cross-over between many of these categories. For example, Twitter could fall under micro-blogging, but it also belongs under social networking. The key to success with social media is to first define your institutional needs and learning strategy - then select the category of media which best supports these. 
The 21st century skills for learners are collaboration, critical thinking, creative thinking and communication. To raise students armed with the 21 st century skills, the properties of adaptive classroom setting must aim at the following objectives:

- Students interact with teacher and other students

- Students talk about what they are doing

- Interaction is largely meaning-based

- Emphasis is placed on deep conceptual learning

- Hands-on activities lead to understanding

- Learning results are co-constructive

- Students can explain their own reasoning and critique the reasoning of others

The human computer lab with the university of Hawaii completed a study which anticipated the development of "new embedded technologies that can be a seamless part of any physical object in schools" which can then be used to support classroom learning" . One example of technology being used to facilitate learning when it is viewed as a "constructive and social activity" is the internet. As the internet "increasingly gained in popularity as a communication channel" and Web 2.0 applications become more common "attention switched to social interaction and its relevance for learning" [7].

A study on adaptable spaces and their impact on learning identified four key constructs that affect student learning; Basic Human Need, Teaching, Learning, and Engagement ${ }^{[8]}$.

A private social network can be found for educators who are worried about the security of personal information. Educators will have their own private social network in which they can invite their students. The younger students do it under the supervision of their parents, since their safety and securities are essential. They can discuss things related to lessons and develop their education. Communication with administrators, students and parents will be very easy. They can give personalized instructions. Teachers will have tools to communicate with parents and students. Those tools include setting homework, sending documents, creating calendars and doing students' assessments.

Schoolfy sends real time notifications to students and parents with no effort. The system generates automatic notifications so that the educators do not need to worry about anything. And to make things easier, parents convey everything related to the education of their children comfortably. Social learning system assigns students to classes and small groups, organizing teacher tasks, grading and returning assignments electronically, providing parents with real-time notifications.

Schoolfy comes with addendum as a support tool wherein it can convert all examinations in educational materials into interactive documents, exercises are automatic that are customized for each student. Saving their information and qualifications are easily done even if the student answers by hand.

By using a social learning system like Schoolfy, teachers can spend most of their time on what really matters to students. They can think of each and every student's development, helps them by giving individual instructions, make interesting lesson presentations and they also have much more free time for them.

\section{Analysis}

There's no doubt in that educational platforms will undergo steps of transformation to answer to the human calls. However, the current educational platform must work with the today's state of art in smart technology available to schools. Current smart technologies are smart boards, smart pads, Web2.0 and their furniture. 
Schoolfy was used to blend a social learning system into classroom language teaching and learning. It uses a social media and collaboration tool to share and manage what students learned and produced in the classes. The organization of Schoolfy is based on procedural approach in system development and management. Thus, the blending of new technology into existing structure can be explained in the framework of context-processoutcomes mediated by the feedback loop. The Figure 2 demonstrates the organizational flow of the framework wherein the context includes environment and structure, the process is described as relational practices connect social involvement and content management, and outcomes contain relational and technical qualities. The outcomes loop back to the context where the process started as in Figure 2.

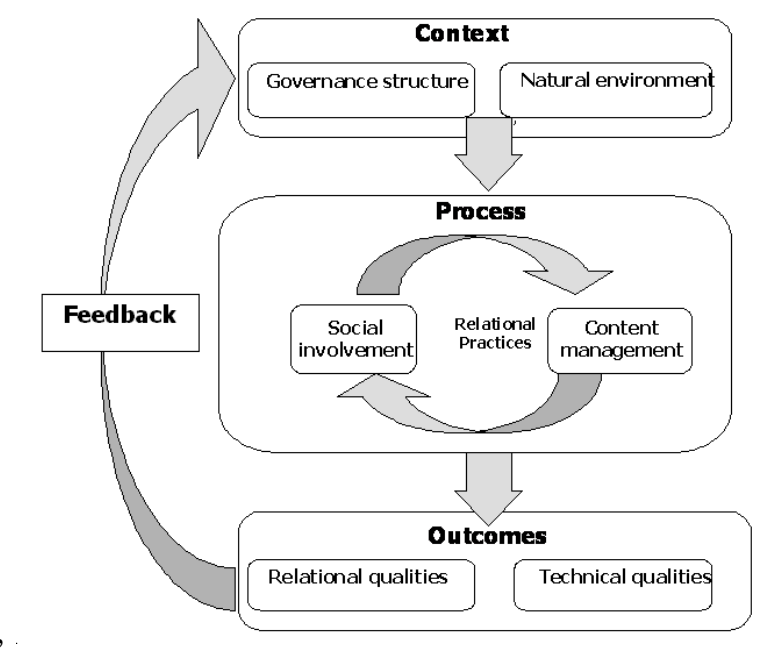

Figure 2. Context-Process-Outcomes Procedure

It is important to recognize the educational platform as a second teacher and there is a good pedagogical value of an adjustable platform just like an effective teacher move around the classroom to ask and confirm students' understanding. The impact of physical comfort brought by the adjustable platform is support of pedagogy, and designing flexible, comfortable learning spaces enhances the experience of both teacher and students. When classroom environments are easily adjustable to allow for comfort and practicality, students' learning experience was heightened with reduced learning comfort (27\%), being able to understand better $(26 \%)$, and interact with others better $(22 \%)$. Besides students being better serviced by an adjustable educational platform centered around the smart technology also reported the benefits of increased students' responses, better access to internet connections, improved ability to interact with other students and the heightened awareness of their knowledge to the real world.

An example of this heightened awareness is that students using a curation tool such as Paper.li to sort and evaluate information before sharing it with others or collaborating on a Wikispace page with another student, both of which focus instructions on the active construction of knowledge and building communities and social interaction. In the classroom of the future technology will no longer limit collaboration and community thinking solely to the inside of the classroom but will allow for these activities to occur outside the classroom in the real world. Students could learn English "using a large HDMI monitor and High Definition sound system, along with a web connection could take them on virtual field trips once a month, wearing a wen camera that shows students sites, such as the Capital Mall" while also allowing them to practice their English with native speakers. 
The effect of the experiential learning using social learning system done in the fall semester of year 2013 was positive in all four language skills measured on 38 college students including listening, speaking, reading and writing as in table 1.

Table 1. Effect of Experiential Learning

\begin{tabular}{|l|l|l|l|l|l|}
\hline Domain & \multicolumn{2}{|l}{ Mean d } & SD d & $\begin{array}{l}95 \% \\
\text { LCI }\end{array}$ & $\begin{array}{l}95 \% \\
\text { UCI }\end{array}$ \\
\hline listening & 1.12 & 0.72 & 0.92 & 1.32 \\
\hline speaking & 0.87 & 0.37 & 0.69 & 0.92 \\
\hline reading & 1.34 & 1.01 & 1.03 & 1.62 \\
\hline writing & 1.27 & 0.92 & 0.85 & 1.59 \\
\hline
\end{tabular}

Table 1 shows that the overall effect sizes are bigger than .8 in all skills including listening, speaking, reading and writing indicating that the effect size is big. Most notably, reading and writing were enhanced due to the active social learning system allow students to collect information mostly in reading and partially in listening for what they learn and collaborate with each other and others in writing.

\section{Conclusion}

The educational platform using social learning system requires of changes of teachers in both their practices of teaching and their attitudes. Most of all, though, the change demands of the perception and use of the educational platform. The classroom equipped with social learning system is increasing fast. The physical spaces which make up the classroom, the educational technologies we use, and the teaching pedagogy we subscribe to are not static, and as educators it is critical for use to continue learning about what the classroom of the future will look like. No matter where we teach these changes will affect us all. As Mäkitalo-Siegl, Zottmann, Kaplan \& Fischer assert "teachers themselves should be more open to new pedagogical models and the development of technology as well as be willing to regularly update their knowledge by participating in in-service education and reading current research literature"[7].

The societal development of humans enable us to build a conceptual world using the electronic technology. For example, computers (a mathematical machine) are a conceptual world constructed by the people. It is a cold conceptual world based on a human reasoning power devoid of humanistic emotions and attractions. This is where the separation between human cognition and computational cognition begins. Natural language is a humanistic product as much as a computer language is. Natural languages are full of ambiguities on all their facades: lexical, syntactic and pragmatic. Natural languages are full of euphemisms and derogatory showing the attitudes of the speakers on the event they are describing. Natural languages evolved around the humane needs of eulogies and despises from the very beginning of the societal formation of humane villages. However, the computational languages are devoid of ambiguities and other humane linguistic needs.

Computers were invented as a mathematical tool. When a tool is made, the function is conceptualized before the existence of the tool, which is drastically different from the human existence. In case of humans, the existence precedes the function which is contrary to the existence of tools including computers. Thus, the conception of educational platform must start from the sharp distinction between humans and tools. This implies that educational platform using smart technology must result from the functionalities of human interaction in a classroom setting. Since computers are conceptualized as a logic 
machine, it is a rule-based system. However, a large portion of classroom interaction is meaning-based and rules are a byproduct of processing meaning.

One thing obvious in education is everything will change except teachers. Students will change, contents and methods will change, educational platform will change to include the current technological advancement. The best way to cope with these changes is that teachers stay open-minded and embrace these changes.

\section{References}

[1] P. Bourdieu, "Outline of a Theory of Practice. Cambridge", Cambridge University Press, (1977).

[2] A. Giddens, "The constitution of society: Outline of the theory of structuration", University of California Press, (1984).

[3] J. Lave, "Cognition in practice: mind, mathematics, and culture in everyday life", Cambridge University Press, (1988).

[4] M. Foucault, "Power/Knowledge: Selected interviews and writings", (1980).

[5] L. Vygotsky, "Mind in society: Development of higher psychological processes", Harvard University Press, (1978).

[6] The Human Computer Interaction Lab, "New embedded technologies in school", Technical Report \#2006-3, University of Hawaii, (2006).

[7] K. Mäkitalo-Siegl, J. Zottmann, F. Kaplan and F. Fischer, "Classroom of the future orchestrating collaborative spaces", Sense Publishers, (2010).

[8] The Herman Miller Company, "Adaptable spaces and their impact on learning", Retrieved on December 20, 2013 from http://www.hermanmiller.com/research/research-summaries/adaptablespaces-and-their-impact-on-learning.html, (2011).

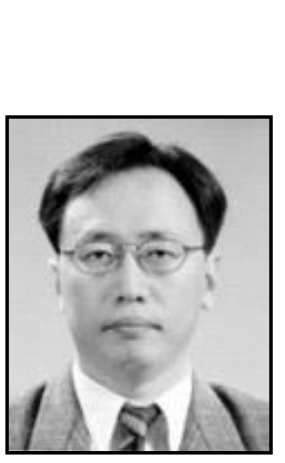

\section{Author}

Jeong-ryeol Kim, He has a $\mathrm{Ph} . \mathrm{D}$. in applied linguistics from University of Hawaii and has been a professor of English at Korea National University of Education (KNUE) teaching methodology, integrated content and language teaching, English linguistics. He served as the president of Korea Association of Foreign Languages Education for 2013-2014 and was the president of Korea Association of Primary English Education for 2010-2011 and the president of KOTESOL back in 1996-1997. He was involved in different government projects in curriculum, textbooks and English education using information and communications technology. He has published books on classroom English, teaching methodology, English curriculum, English classroom observation and analysis to name a few. He has published numerous articles in the area of elementary English education and technology enhanced English teaching. 